Supporting Information

for

\title{
Modeling the Competitive Dissociation of Protonated 2,3-Butanedione. The Enthalpy of Formation of Methylhydroxycarbene
}

\author{
by \\ Xinping Liu, Michael L. Gross and Paul G. \\ Wenthold
}

Metastable ion kinetic energy spectrum of the decomposition of $\mathbf{1} \mathbf{H}^{+}$. 
Figure S1. MIKE Spectrum of the Decomposition of Protonated Butanedione

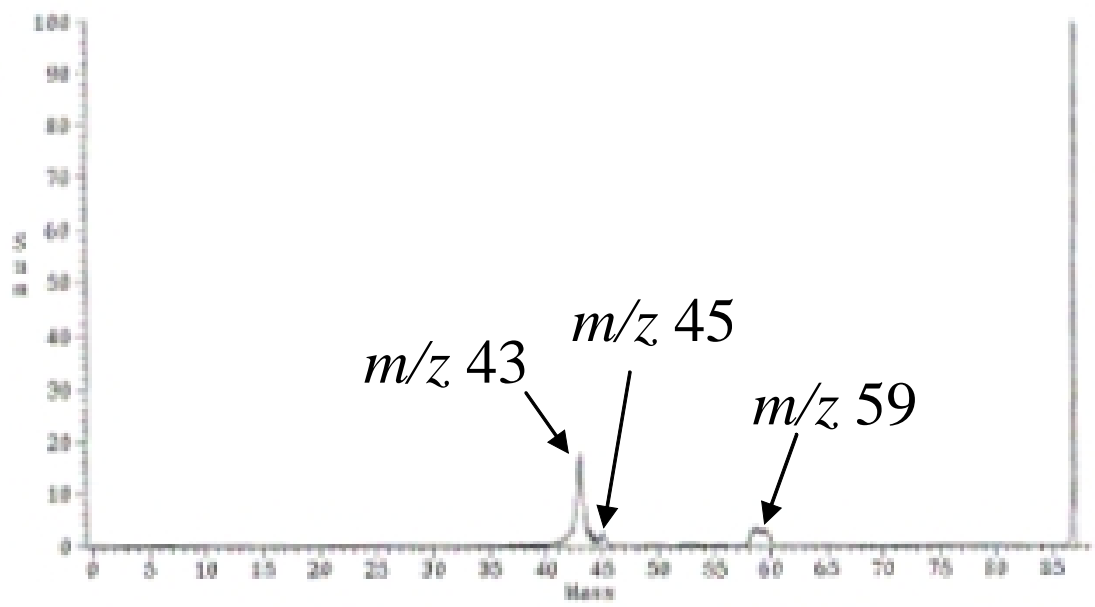

